\title{
Second Language Interferes with Word Production in Fluent Bilinguals: Brain Potential and Functional Imaging Evidence
}

\author{
Antoni Rodriguez-Fornells ${ }^{1,2,3}$, Arie van der Lugt ${ }^{1}$, Michael Rotte ${ }^{1}$, \\ Belinda Britti ${ }^{1}$, Hans-Jochen Heinze ${ }^{1}$, and Thomas F. Münte ${ }^{1}$
}

\begin{abstract}
Bilingual individuals need effective mechanisms to prevent interference between their languages. Using event-related brain potentials (ERPs) and functional magnetic resonance imaging (fMRI), we present evidence for interference of phonological information from the nontarget language in German-Spanish bilinguals. A tacit picture-naming task was used in which bilinguals and monolinguals had to make speeded responses based on the first letter of the picture's name in the target language. In one condition, subjects were required to respond when the name began with a vowel and to withhold a response
\end{abstract}

if it started with a consonant. Stimuli had been selected such that in half of the trials, the names in both languages necessitated the same response, whereas in the other half, responses were different for the two languages. For the bilinguals, the language in which the stimuli had to be named was changed after each block. Bilinguals showed phonological interference compared with monolingual performance, which was evident in their performance, ERPs, and fMRI patterns. Nonlanguagespecific brain areas such as the left middle prefrontal cortex were found to be crucial for the control of interference.

\section{INTRODUCTION}

Fluent bilinguals are able to generate and comprehend utterances in the selected language without apparent effort. In spite of numerous behavioral studies, it is still not entirely clear how such subjects regulate the activation of both lexicons. This ability is even more puzzling in light of recent neuroimaging studies demonstrating overlapping neuroanatomical representation of languages (Hernandez, Dapretto, Mazziotta, \& Bookheimer, 2001; Hernandez, Martinez, \& Kohnert, 2000; Chee, Caplan, et al., 1999; Chee, Tan, \& Thiel, 1999; Klein, Milner, Zatorre, Zhao, \& Nikelski, 1999; Price, Green, \& von Studnitz, 1999; Perani et al., 1998).

Rather than addressing the brain representation of the two languages in bilinguals, the present study therefore aims at providing neuroscientific data on how they administrate their languages in a modified picturenaming task by taking advantage of the high temporal resolution of event-related brain potentials (ERPs) and the high spatial resolution of event-related functional magnetic resonance imaging (fMRI). Specifically, the combination of both techniques allows to delineate the time course of the effects of interference during

${ }^{1}$ Otto-von-Guericke University, Magdeburg, ${ }^{2}$ University of Barcelona, ${ }^{3}$ Institució Catalana de Recerca i Estudis Avançats (ICREA)

language production in bilinguals and the brain regions engaged in coping with this interference.

\section{Models of Language Production}

When we wish to name an object, there are at least two distinct stages en route from the concept to articulation (Dell \& O'Seaghdha, 1992; Schriefers, Meyer, \& Levelt, 1990; Levelt, 1989). In the first stage, lexical selection, conceptual or semantic activation drives the selection of abstract lexical candidates (called lemmas) containing the name's syntactic features (Levelt, 1989; Kempen \& Huijbers, 1983). In the second stage, phonological encoding, the lemma is used to retrieve the detailed phonological form of the target word also know as lexeme (Kempen \& Huijbers, 1983). Thus, mapping a concept to sound requires at least three different kinds of representations: semantic, syntactic, and phonological (Levelt, Roelofs, \& Meyer, 1999).

Temporal estimates regarding the activation of different representational levels have been made based on reaction time studies using picture-naming tasks (Petersen \& Savoy, 1998; Dell \& O’Seaghdha, 1992; Levelt, Schriefers, et al., 1991; Schriefers et al., 1990). In a recent review, Indefrey and Levelt (2004) have provided the following estimates for the different stages as follows: picture presentation at $0 \mathrm{msec}$, lexical concept selection $175 \mathrm{msec}$, target lemma selection $250 \mathrm{msec}$, phonological segments $330 \mathrm{msec}$, phonological word $455 \mathrm{msec}$, articulatory 
scores 600 msec. Each of these estimates represents the median of a range of numbers derived from experiments using different methodologies. Thus, Indefrey and Levelt (2004) caution against a too rigid interpretation of these numbers.

This sequence of events during language production has received support from ERP measurements suggesting that semantic information is encoded about 120 msec before phonological information (e.g., van Turennout, Hagoort, \& Brown, 1997) and that syntactic encoding is encoded about $40 \mathrm{msec}$ before phonological information (van Turennout, Hagoort, \& Brown, 1998). Our own group obtained similar estimates using a brain potential component linked to response inhibition, called the N200 no-go component (RodriguezFornells, Schmitt, Kutas, \& Münte, 2002; Schmitt, Schiltz, Zaake, Kutas, \& Münte, 2001; Schmitt, Münte, \& Kutas, 2000). This component manifests itself as an increased negativity over frontal sites to no-go responses compared with go responses (Thorpe, Fize, \& Marlot, 1996; Pfefferbaum, Ford, Weller, \& Kopell, 1985) and has been related to an on-line inhibitory process emanating from structures in the prefrontal cortex with right hemisphere dominance (Liddle et al., 2001; Menon, Adleman, White, Glover, \& Reiss, 2001; Garavan, Ross, Li, \& Stein, 2000; Garavan, Ross, \& Stein, 1999; Konishi et al., 1998, 1999).

\section{Language Production in Bilinguals}

Fluent bilinguals seem to have the capacity to switch from one language to the other and to apparently separate both languages completely (switching proficiency). In spite of this ability, code switching is also often observed (i.e., bilinguals sometimes introduce words from the other language into the language that they are currently using). It has been argued that both switching proficiency and code switching are related to the degree of activation of the target and nontarget languages at a given moment (Grosjean, 1997; Paradis, 1989). In addition to a bilingual's degree of proficiency in L2, the bilingual status of the interlocutor and the communicative setting appear important for the degree of code switching, in extreme cases leading to "hybrid languages" like "Spanglish." At the other end of the continuum, that is, in the "monolingual mode," a smaller number of intrusions is observed, giving the appearance of complete independence of both languages, as if the nontarget language is switched off. According to a model proposed by Poulisse and Bongaerts (1994), each word possesses a "language tag" linking it to a particular language. These language tags would permit to activate only a limited set of lexical items, mostly from the target language but also some from the nontarget language, at any given time. Other authors (e.g., de Bot, 1992; Green, 1986), on the other hand, have proposed that lexical items belonging to different languages can be completely activated or deactivated.

Although there is a general agreement that lexical access (lemma activation) can occur in parallel in both languages at least to some degree, it is less clear if the corresponding phonological forms are also activated. If the language-selection mechanism acts at the lemma level, no phonological activation should be observed for the nontarget language. On the other hand, if selection is operating at a later stage, the phonological form belonging to the nontarget language word should receive at least partial activation. Three different chronometric studies have addressed this issue with contradictory conclusions. In one study on Dutch-English bilinguals, Hermans, Bongaerts, de Bot, and Schreuder (1998) suggested that, although bilinguals cannot avoid interference during lemma activation, they behave as monolinguals when the target phonological form has to be recruited. Two other recent studies (Colomé, 2001; Costa, Caramazza, \& Sebastian-Galles, 2000) reached the opposite conclusion: For example, Colomé (2001) required Catalan-Spanish bilinguals to decide whether a specific phoneme (e.g., "m") was present in the Catalan name of a picture (e.g., taula [table]). Interestingly, subjects were slower to answer "no" when the phoneme to be monitored was part of the Spanish (i.e., nontarget language) word (e.g., mesa [table]), than if it was neither part of the Catalan nor the Spanish word. This implied that the phonological representation of the nontarget language word was active.

\section{Objectives}

The main goal of the current study was to assess to which degree bilinguals experience interference from the nontarget language when naming a picture in the target language. To avoid vocalization artifacts during electroencephalogram and fMRI acquisition, a variant of the go/no-go tacit picture-naming task was employed (see Rodriguez-Fornells, Schmitt, et al., 2002; Schmitt, Münte, et al., 2000; van Turennout et al., 1998). This task required subjects to access the phonological representation of a picture as they had to decide whether the name of the depicted object/animal began with a consonant or a vowel. For example, in one condition, subjects were required to respond when the German name of the picture began with a consonant and to withhold a response for words starting with a vowel. Stimuli had been selected such that in half of the trials the names in both languages (Spanish and German) would lead to the same response (either go or no-go responses, coincidence condition), whereas in the other half, responses were different for the two languages (noncoincidence condition, see Figure 1 for an example).

Obviously, this task makes the assumption that it is necessary to access the phonological representation of the word to make the proper vowel/consonant classifi- 


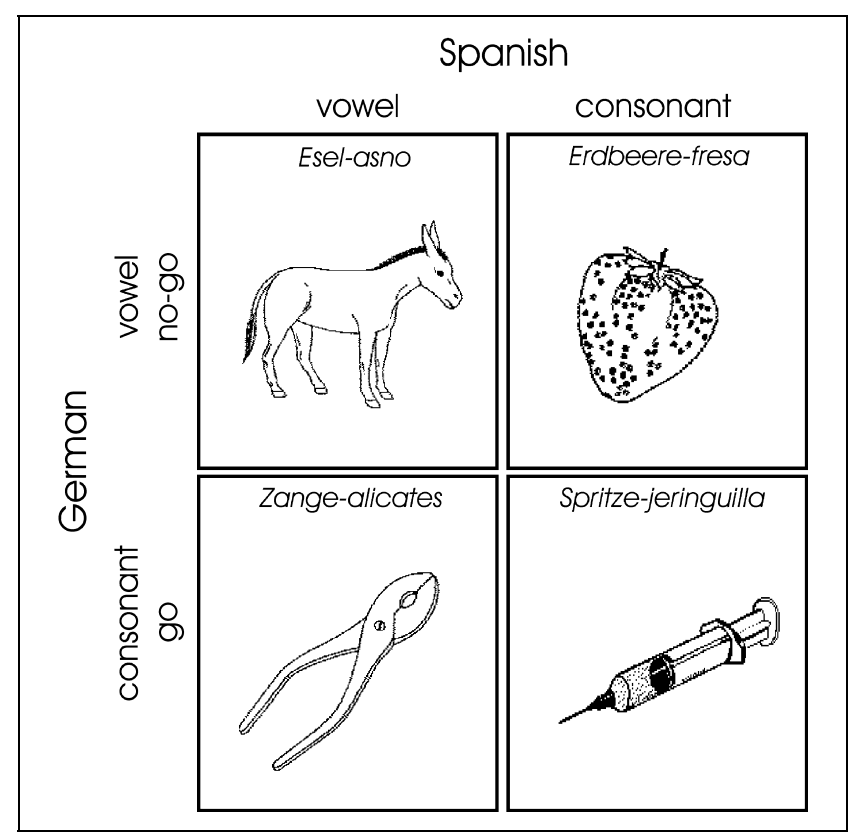

Figure 1. Examples for picture stimuli. In this particular case, subjects were required to press a button if the name of the picture began with a consonant in German (go trials) and to refrain from responding when the German name began with a vowel (no-go trials). Note that half of the pictures coincided with regard to the vowel/consonant classification between the two languages and the other half did not.

cation. This appears justified by results of Wheeldon and Levelt (1995) who demonstrated that phoneme monitoring in a language production task is sensitive to the time course of phonological encoding. With regard to the scientific question at hand data from the noncoincidence condition is most important: In the bilingual subjects, this condition should lead to detectable brain effects of interference, if the phonological representation of the nontarget language name was activated.

\section{RESULTS}

\section{Performance Data}

Reaction times and percentage correct responses are shown in Table 1. In the German naming task, bilinguals were slower in both experiments [ERP: $F(1,22)=84$, $p<.001$; fMRI: $F(1,20)=7.7, p<.012]$. No main effects of phonological coincidence were obtained [ERP: $F(1,22)<1$; fMRI: $F(1,20)<1$ ] . A Coincidence $\times$ Group interaction was seen only in the ERP experiment $[F(1,22)=15.4, p<.001$; fMRI: $F(1,20)=1.35, p>.2]$.

For the bilingual subjects, reaction times for the Spanish and German naming tasks were compared revealing a significant main effect coincidence in both experiments [ERP: $F(1,11)=5.2, p<.05$; fMRI: $F(1,10)=$ $6.1, p<.05]$. A main effect of language was obtained only in the ERP experiment $[F(1,11)=7.2, p<.05]$ and no Language $\times$ Coincidence interaction was seen.

With regard to the percentage of hits in the gocondition, a significant group effect emerged in the ERP experiment $[F(1,22)=39.3, p<.001$; fMRI: $n s]$. Although the main effect of coincidence was not significant, a significant interaction between Coincidence $\times$ Group was present in the ERP study $[F(1,22)=5, p<$ $.05]$ but not in the fMRI study $[F(1,20)=2.3, p>.15]$. Comparing the percentage of hits between languages for

Table 1. German and Spanish Picture-naming Performance in Both Groups

\begin{tabular}{|c|c|c|c|c|c|c|}
\hline & \multicolumn{2}{|c|}{ Go $(R T \pm S D$, msec $)$} & \multicolumn{2}{|c|}{ Go (\% Correct Responses) } & \multicolumn{2}{|c|}{ No-go (\% Errors) } \\
\hline & Coincidence & Noncoincidence & Coincidence & Noncoincidence & Coincidence & Noncoincidence \\
\hline \multicolumn{7}{|c|}{ A. ERP Experiment } \\
\hline \multicolumn{7}{|l|}{ German naming } \\
\hline Monolingual & $659 \pm 62$ & $638 \pm 62$ & $95.4 \pm 4.8$ & $96.2 \pm 4.4$ & $4.7 \pm 3.2$ & $4.2 \pm 4$ \\
\hline Bilingual & $831 \pm 40$ & $845 \pm 35$ & $83.5 \pm 9.9$ & $80.6 \pm 9.7$ & $8.1 \pm 2.7$ & $11.2 \pm 4.4$ \\
\hline \multicolumn{7}{|l|}{ Spanish naming } \\
\hline Bilingual & $813 \pm 36$ & $825 \pm 34$ & $82.3 \pm 10$ & $76.4 \pm 11$ & $6.5 \pm 3.7$ & $11.9 \pm 3.6$ \\
\hline \multicolumn{7}{|c|}{ B. fMRI Experiment } \\
\hline \multicolumn{7}{|l|}{ German naming } \\
\hline Monolingual & $747 \pm 118$ & $741 \pm 62$ & $83.1 \pm 5.7$ & $85.2 \pm 5.4$ & $9.0 \pm 4.2$ & $8.0 \pm 4.2$ \\
\hline Bilingual & $844 \pm 40$ & $860 \pm 35$ & $81.4 \pm 10.8$ & $81.6 \pm 10.2$ & $9.1 \pm 3.4$ & $7.8 \pm 3.4$ \\
\hline \multicolumn{7}{|l|}{ Spanish naming } \\
\hline Bilingual & $819 \pm 36$ & $859 \pm 34$ & $80.6 \pm 10.1$ & $80.2 \pm 11.1$ & $10.1 \pm 3.5$ & $10.4 \pm 4.5$ \\
\hline
\end{tabular}


the bilingual group, a significant main effect for coincidence was seen in the ERP study $[F(1,11)=9.8, p<.01$; fMRI: $n s$ ], whereas the Language $\times$ Coincidence interaction was significant in the fMRI study [ERP: $F(1,11)=$ $3.1, p>.1$; fMRI: $F(1,10)=6.08, p<.05$ ]

\section{Event-related Brain Potentials}

Figure 2 shows the ERPs to go and no-go trials from the German condition. An early fronto-centrally distributed negative deflection at $100 \mathrm{msec}$ is followed by a positivity at around 200 msec. After these early components, a negative deflection maximal for frontal locations and considerably broader for the bilingual subjects is seen. For the no-go trials, an additional negativity (N200 effect) occurs between 300 and $600 \mathrm{msec}$ in the monolinguals, which is maximal at right frontal locations. By

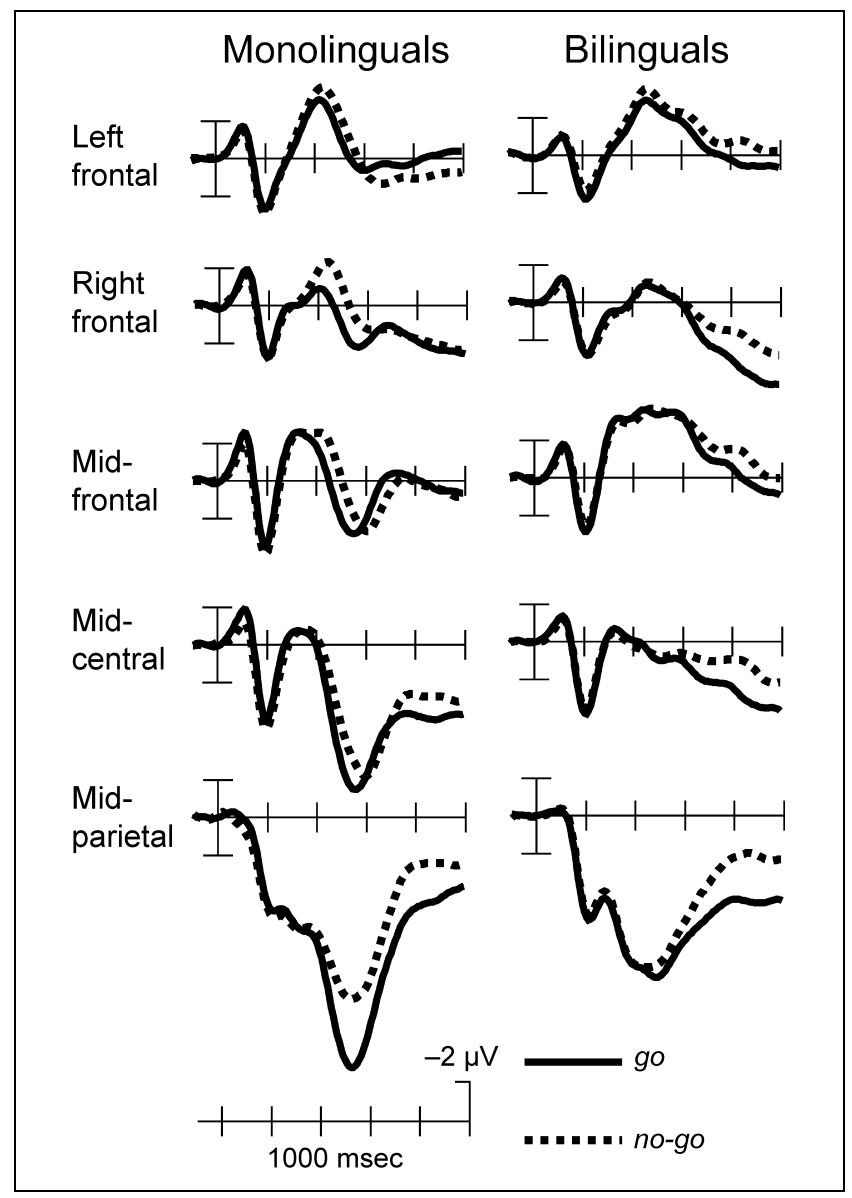

Figure 2. Grand averages for monolingual and bilingual groups in both the go and no-go conditions for the midline and fronto-temporal locations. For these averages, trials with coincidence and noncoincidence with regard to the letter/vowel task were collapsed. In the monolingual group, an enhanced negativity is clearly present in the 400- to 600-msec range for no-go trials, whereas for the bilinguals no-go trials were associated with a somewhat later negativity. In addition, waveforms of the bilingual group showed a more negative time course between 400 and 700 msec. contrast, a no-go effect in the bilinguals is seen only beyond $600 \mathrm{msec}$. At posterior locations, a clear positive component with a peak latency of about $500 \mathrm{msec}$ and larger for the go trials is present. A set of analyses of variance (ANOVAs) with group, go/no-go, and coincidence as factors is summarized in Table 2. Highly significant main effects of the go/no-go factor emerged from 400 to $600 \mathrm{msec}$ onward. Although there was no main effect of coincidence, a Group $\times$ Coincidence interaction was revealed for the 400- to 600- and 600to $800-\mathrm{msec}$ time windows. Figure 3 shows that this interaction arises because ERPs in the noncoincidence condition were more negative than those in the coincidence condition in the bilinguals only. Interestingly, this effect occurred somewhat later in the no-go condition giving rise to triple Group $\times$ Coincidence $\times$ Go/No-go interactions in some of the time windows. Group differences were quite dramatic (Figure 4) with the positivity seen in the 500- to 700-msec time range in the monolinguals being greatly attenuated in the bilinguals. This appears to be because of a sustained negativity in the range of 400-700 msec. The difference between the two groups has a midfrontal maximum.

A second set of ANOVAs with language (SpanishGerman), go/no-go, and coincidence was performed in the bilingual subjects (see Table 3). ERPs from the Spanish condition showed the same coincidence effect as those from the German condition (Figure 3, middle and bottom row). Statistically, main effects of coincidence were obtained between 400 and $800 \mathrm{msec}$, reflecting the increased negativity in the noncoincidence condition for both languages (no Language $\times$ Coincidence interaction). The go/no-go effect interacted with phonological coincidence condition, and this interaction remained significant until the end of the epoch.

\section{Event-related Functional Magnetic Resonance Imaging}

Areas activated over the baseline condition (fixation trials) in the German naming condition were very similar in mono- and bilinguals and comprised the fusiform gyrus (bilateral), inferior occipital gyrus (bilateral), left superior parietal lobe, anterior cingulate gyrus, supplementary motor area (SMA) region, left inferior frontal gyrus, and the cerebellum. No differences were found in any of these areas for the group comparisons when a conservative threshold was used $(p<.001$, cluster corrected for 10 voxels; see Figure $5 \mathrm{~A}$ and Table 4 ).

An interesting group difference emerged for the main effect of phonological coincidence (see Figure 5B). Bilinguals activated a large region of the middle left prefrontal cortex (Brodmann's area [BA] 9/46, peak coordinates $-40,36,32, T=3.4, p<.001)$ and the SMA (BA 6, peak coordinates $8,0,68, T=3.3, p<.002){ }^{1}$

A further analysis on the interaction of coincidence and go/no-go factors (Figure 5C) revealed significant 
Table 2. ERP Experiment: Results of ANOVAs ( $F$ Values) Comparing Monolingual and Bilingual Subjects for German Naming

\begin{tabular}{|c|c|c|c|c|c|c|c|c|}
\hline & \multicolumn{2}{|c|}{$200-400 \mathrm{msec}$} & \multicolumn{2}{|c|}{$400-600 \mathrm{msec}$} & \multicolumn{2}{|c|}{$600-800 \mathrm{msec}$} & \multicolumn{2}{|c|}{$800-1000 \mathrm{msec}$} \\
\hline & $M l$ & Ps & $M l$ & Ps & $M l$ & Ps & $M l$ & Ps \\
\hline \multicolumn{9}{|l|}{ Gr } \\
\hline Go & & & $25.2 * * *$ & $57.8 * * *$ & $5.26 *$ & $11.9 * *$ & $11.2 *$ & $19.5^{* * *}$ \\
\hline $\mathrm{Gr} \times \mathrm{Go}$ & & & $17.6 * * *$ & $26.6 * * *$ & & & & \\
\hline \multicolumn{9}{|l|}{$\mathrm{C}$} \\
\hline $\mathrm{Gr} \times \mathrm{C}$ & & & $13.0 * *$ & $11.7 * *$ & $13.4 * *$ & $13.9 * *$ & & \\
\hline $\mathrm{Go} \times \mathrm{C}$ & $7.09 *$ & $10.4^{* *}$ & $9.3^{* *}$ & $13.2 * *$ & & & & \\
\hline $\mathrm{Gr} \times \mathrm{Go} \times \mathrm{C}$ & & & & & $7.3^{*}$ & & $4.9^{*}$ & \\
\hline
\end{tabular}

group differences in the anterior cingulate gyrus (BA 24/ 32, peak coordinates $0,20,32, T=4.75, p<.001$, corrected $p<.02)$.

\section{DISCUSSION}

The main question addressed in this study is whether and to what extent the presence of a second language interferes with naming performance of bilinguals. Specifically, we asked whether phonological features of the picture's nontarget language name would interfere with target language naming implicitly assessed with a go/nogo task. Previous work from our group using a combined ERP-fMRI approach in a bilingual Catalan-Spanish wordreading task had revealed effective suppression of second language interference in bilingual subjects (RodriguezFornells, Rotte, Heinze, Nosselt, \& Münte, 2002).

By contrast, in the present study, behavioral, electrophysiological, and brain imaging results provide clear evidence for cross-language interference in bilinguals in the present task. Bilinguals made more errors and their response latencies were longer by about $100 \mathrm{msec}$ (for the fMRI study) to 200 (ERP study) msec in both languages. More importantly, bilinguals also made less correct responses for pictures that did not match with respect to the class of the initial phoneme in the two languages. This is a clear demonstration of interference at the phonological level during tacit picture naming.

The ERP findings are also consistent with interference between languages. Although for monolinguals, consistent with previous studies (Rodriguez-Fornells, Schmitt, et al., 2002; Schmitt, Münte, et al., 2000), a typical N200 component was observed for the no-go trials with a right-frontal distribution and a peak latency of about $450 \mathrm{msec}$ was found and no effects of coincidence were observed, a different picture emerged for the bilinguals.
Here, the no-go effect was delayed by about 200 msec (i.e., by about the same amount as the reaction time). Crucially, interference manifested itself in the form of an increased negativity found for noncoincidence trials

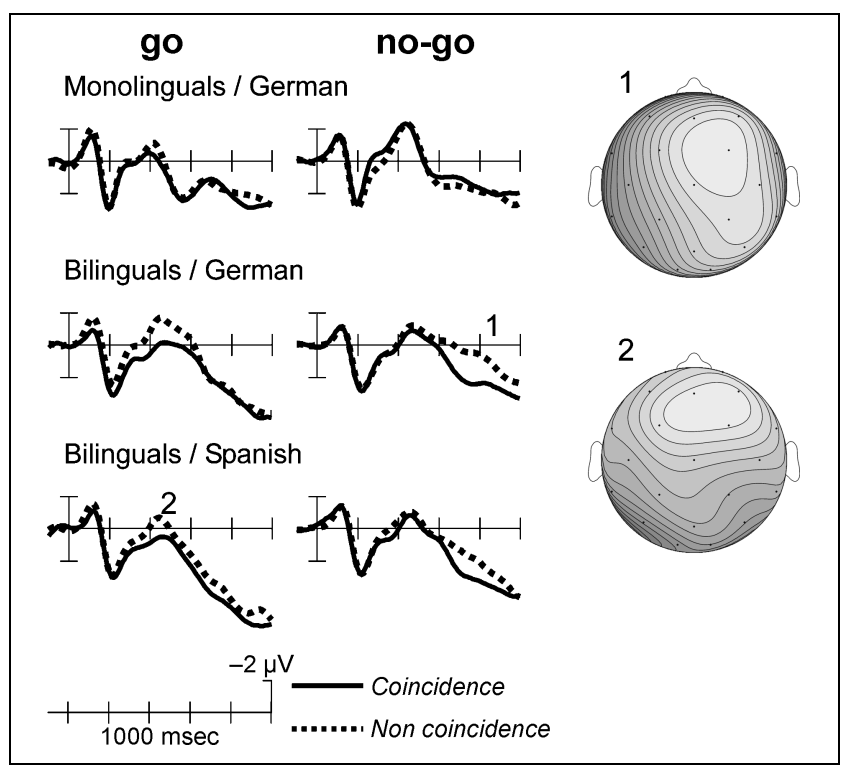

Figure 3. Comparison of ERPs (right fronto-lateral recording site) to words that coincided or did not coincide with regard to the vowel/consonant task in the two languages. Expectedly, there was no coincidence effect in the monolingual German subjects. The bilinguals on the other hand showed an enhanced negativity for noncoincidence trials. This additional negativity occurred between 300 and $600 \mathrm{msec}$ in the go-trials and from $600 \mathrm{msec}$ onward in the no-go trials. The topographical maps depict the distribution of the difference between coincidence and noncoincidence trials for the two languages as indicated by the numbers. In all cases, a frontal maximum of the coincidence effect is seen. Topographical gray scales are relative in each map (from the most positive to negative value): $1,-0.28 /-1.20 ; 2,0.47 /-1.25$. 


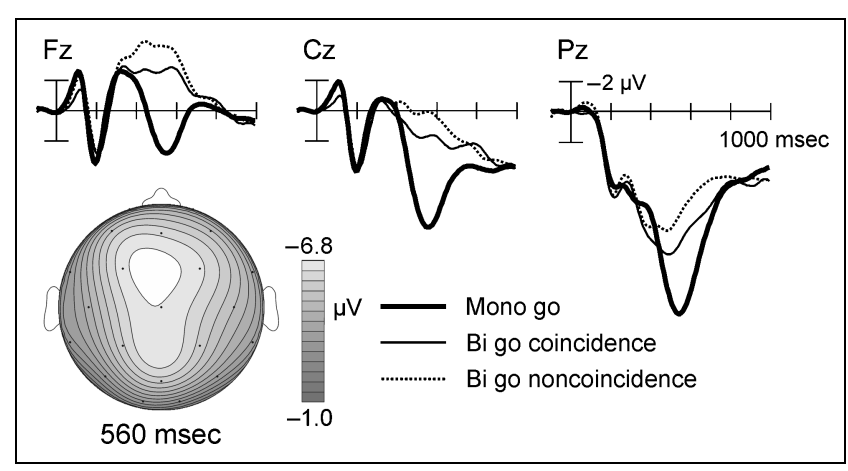

Figure 4. Top: Grand averages for monolingual and bilingual groups are plotted together for go trials from the German naming task. For the bilinguals, the average is broken down according to the coincidence criterion. Bottom: Topographical maps for the difference wave obtained by subtracting the monolinguals' ERPs from the bilinguals' waveforms (coincidence go trials) using isovoltage mapping with spherical spline interpolation. The maximum of the difference is at midfrontal sites.

during German and Spanish conditions in the bilinguals only. This increased negativity is seen in go trials between 300 and $600 \mathrm{msec}$ and considerably later in the ERPs to the no-go responses (Figure 3). The noncoincidence effects in the go-responses thus appears in the latency range of the N200 no-go component seen in monolingual subjects in the present study and in previous studies (Rodriguez-Fornells, Schmitt, et al., 2002; Schmitt, Münte, et al., 2000). It can be interpreted as reflecting partial inhibition of the go response in the active language by the interfering no-go response that would be required for the nontarget language word. By contrast, in the no-go trials the increased negativity due to noncoincidence starts at about $600 \mathrm{msec}$. ERPs to nogo responses should have a reduced amplitude in the range of 300-600 $\mathrm{msec}$, because the nontarget language word would have required a go response. In fact, this is the case for this interval, and the effect of noncoincidence does not arise until after 600 msec.

Functional MRI suggests that the same widespread neural network was recruited for covert language production in both groups of subjects (Figure 5A) including the left inferior frontal gyrus (see also, Murtha, Chertkow, Beauregard, \& Evans, 1999; Price, Wise, et al., 1996). With regard to interference, an interesting group difference emerged for the main effect of coincidence in that bilinguals showed activation of the left prefrontal cortex (BA 9/46) and the SMA (Figure 5B). Interestingly, left middle prefrontal cortex has also been found activated in Spanish-English bilinguals during mixedlanguage naming compared with the blocks, in which only one language was used (Hernandez, Dapretto, et al., 2001; Hernandez, Martinez, et al., 2000). Previous imaging studies have revealed a role of these areas in executive functioning, such as the selection of different response alternatives (Garavan, Ross, Li, et al., 2000; D’Esposito, Detre, Alsop, Shin, Atlas, \& Grossman, 1995), the switching between tasks (Dreher, Koechlin, Ali, \& Grafman, 2002; Dove, Pollmann, Schubert, Wiggins, \& von Cramon, 2000), and the inhibition of irrelevant items held in working memory (Baddeley, Emslie, Kolodny, \& Duncan, 1998).

Thus, bilinguals seem to cope with second language interference during language production by recruiting typical "executive function" brain areas that have been observed in many other experimental contexts. These areas might be crucial in inhibiting the production of the nontarget language word. Anecdotally, most bilingual subjects reported that the nontarget language word "popped up" in their mind, making it hard for them to perform the present task. In addition, a recent case report (Fabbro, Skrap, \& Aglioti, 2000) describes a

Table 3. ERP Experiment: Results of ANOVAs ( $F$ Values) Comparing German and Spanish Naming for the Bilinguals

\begin{tabular}{|c|c|c|c|c|c|c|c|c|}
\hline & \multicolumn{2}{|c|}{$200-400 \mathrm{msec}$} & \multicolumn{2}{|c|}{$400-600 \mathrm{msec}$} & \multicolumn{2}{|c|}{$600-800 \mathrm{msec}$} & \multicolumn{2}{|c|}{$800-1000 \mathrm{msec}$} \\
\hline & $M l$ & Ps & $M l$ & Ps & $M l$ & Ps & $M l$ & Ps \\
\hline $\mathrm{L}$ & & & $6.4^{*}$ & $8.6^{*}$ & $23.7 * * *$ & $30.1 * * *$ & $17.1 * *$ & $17.6 * *$ \\
\hline Go & & & $46.2 * * *$ & $27.9 * * *$ & $34.8 * * *$ & $37.9 * * *$ & $20.3^{* * *}$ & $29.9 * * *$ \\
\hline $\mathrm{C}$ & & $6.3^{*}$ & $13.6 * *$ & $16.0^{* *}$ & $20.4 * * *$ & $27.3^{* * *}$ & & \\
\hline $\mathrm{L} \times \mathrm{Go}$ & & & $4.9 *$ & & & & & \\
\hline $\mathrm{L} \times \mathrm{C}$ & & & & & & & & \\
\hline $\mathrm{Go} \times \mathrm{C}$ & & & $5.6^{*}$ & $14.9^{* *}$ & $6.5^{*}$ & & $6.1^{*}$ & $4.8^{*}$ \\
\hline $\mathrm{L} \times \mathrm{Go} \times \mathrm{C}$ & & & & & & & & \\
\hline
\end{tabular}

All $F$ S have $d f=1,11$. See legend of Table 1 . Effects of the topography factors and their interactions with the factors were omitted. $\mathrm{L}=$ language; $\mathrm{Go}=$ go/no-go; $\mathrm{C}=$ coincidence; $\mathrm{Ml}=$ midline; $\mathrm{Ps}=$ parasagittal; empty cells = nonsignificant.

$* p<.05$.

$* * p<.01$

$* * * p<.001$. 
Figure 5. (A) Comparison of all conditions against baseline for monolinguals $(n=11)$ and German-Spanish bilinguals $(n=11)$. Activations are rendered on a T1-weighted single subject MNI template as provided by SPM. Notice the converge pattern of activation between both groups. All differences are illustrated in the figure, $p<.001$. (B) Axial views of the group differences in standard stereotactic space identified for the crucial contrast phonological noncoincidence minus coincidence condition. The axial views presented were superimposed on the mean anatomical image formed averaging for all 22 subjects T1 structural MRI scans mapped into normalized MNI space. Values in the color scale refer to the $T$ values of the corresponding contrast. Notice the differential recruitment of middle frontal gyrus (left hemisphere) and SMA region in this comparison. (C)

Activations of the left middle frontal gyrus rendered on a T1-weighted single-subject MNI template (differences illustrated in the rendered image, $p<.01)$ as a result of contrasting the interaction of coincidence and go/no-go factors.

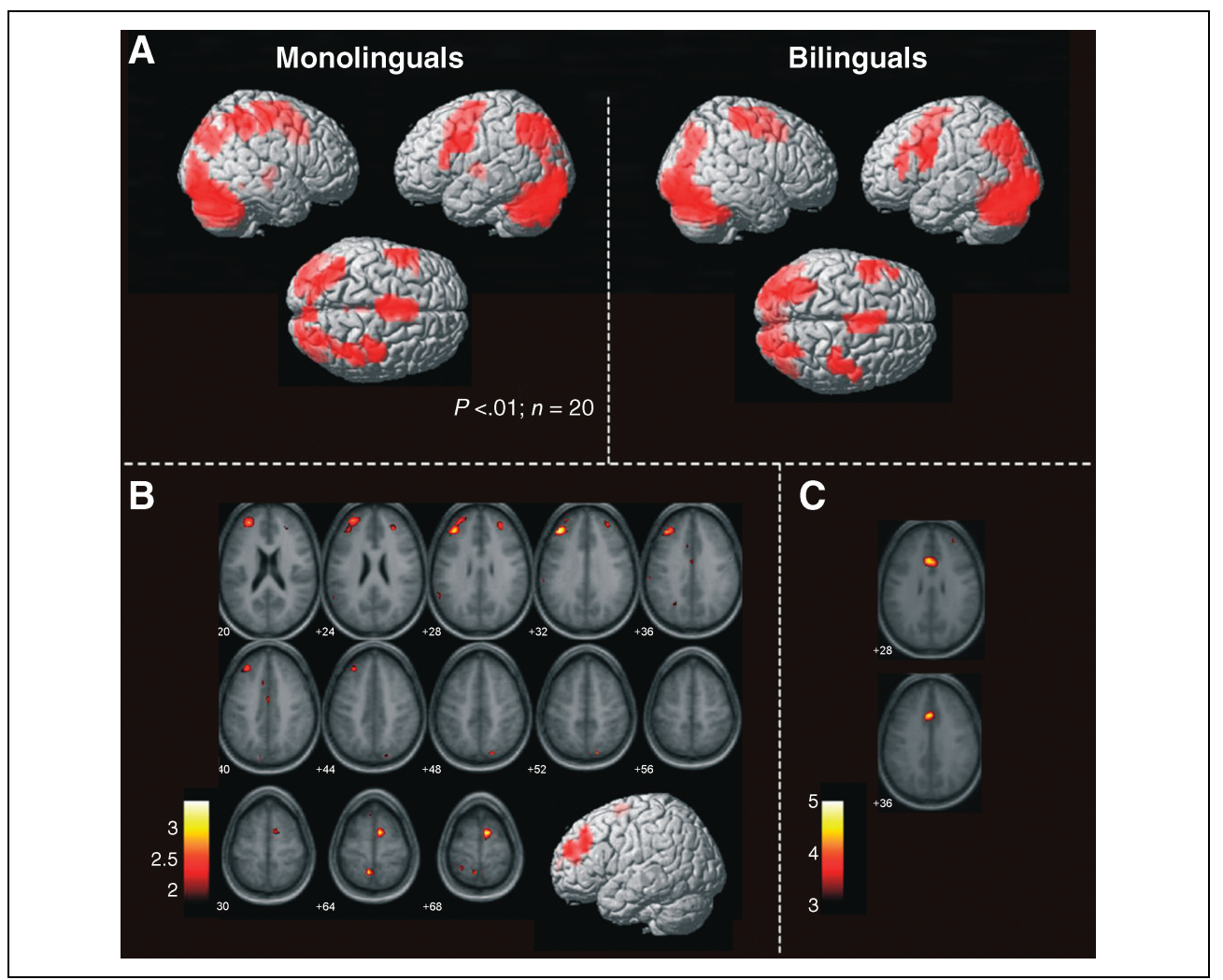

patient with a lesion encompassing the left prefrontal cortex who pathologically switched between his two languages, Friulian and Italian.

Another brain area distinguishing bilingual from monolingual subjects in the fMRI study is the anterior cingulate cortex (ACC, Figure 5C). The marked overall group differences in the ERP study (Figure 4) also had a medial frontal maximum pointing to mesial frontal generators such as the ACC. Different functional neuroimaging studies have shown that this region is active when (1) a prepotent response tendency has to be overcome, like in the Stroop task (Pardo, Pardo, Janer, \& Raichle, 1990), (2) when the response is undetermined, as in verb fluency tasks (Frith, Friston, Liddle, \& Frackowiak, 1993), and (3) when committing errors (Carter, Braver, et al., 1998). A recent model considers that this region evaluates the demand or need of cognitive control by monitoring for the occurrence of conflict or interference in the processing of two stimuli or responses (Carter, Macdonald, et al., 2000; Botvinick, Nystrom, Fissell, Carter, \& Cohen, 1999). Under the current experimental conditions, ACC activity in the bilinguals probably reflects processes engaged to monitor response conflict. In a functional neuroimaging study in German-English bilinguals (Price, Green, et al., 1999), increased activation was found in the ACC when translating visually presented words. Although the authors interpreted the ACC activity as related to the inhibition of the nontarget language word, their data would also be consistent with a monitoring account.

Clearly, only models that incorporate partial activation of the nontarget language items and more specifically their phonological representation are consistent with the present results. To reconcile the present data with serial models with discrete processing stages (Levelt, Roelofs, et al., 1999; Levelt, Schriefers, et al., 1991), it has to be assumed that lemma selection and the subsequent activation of the phonological representation occur in parallel in the two languages. That this might indeed be the case is indirectly suggested by recent experiments that investigated the production of a word that has a near-synonym. This situation is similar to the bilingual case in that strong competition between two lemmas should exist. It was found that both the target lemma 
Table 4. fMRI Experiment: Brain Regions Showing Event-Related Changes for All Conditions Pooled Together against Baseline

\begin{tabular}{|c|c|c|c|c|c|c|}
\hline \multirow[b]{2}{*}{ Brain Region } & \multirow[b]{2}{*}{$B A$} & \multicolumn{3}{|c|}{ Stereotactic Coordinates } & \multirow[b]{2}{*}{ T Peak } & \multirow[b]{2}{*}{$p<$ Corrected } \\
\hline & & $x$ & $y$ & $z$ & & \\
\hline \multicolumn{7}{|l|}{ Monolinguals } \\
\hline R fusiform $G$ & $19 / 37$ & 36 & -84 & -16 & 8.74 & .001 \\
\hline L fusiform $G$ & $18 / 19$ & -32 & -28 & -20 & 10.4 & .001 \\
\hline L SPL & 7 & -28 & -68 & 36 & 6.07 & .005 \\
\hline Cingulate G/SMA & $32 / 6$ & 0 & 8 & 44 & 8.98 & .001 \\
\hline L inferior frontal $G$ & $44 / 45$ & -56 & 12 & 36 & 6.14 & .025 \\
\hline L cerebellum & & -24 & -52 & -40 & 8.08 & .001 \\
\hline $\mathrm{R}$ cerebellum & & 28 & -68 & -36 & 13.61 & .001 \\
\hline \multicolumn{7}{|l|}{ Bilinguals } \\
\hline L fusiform $G$ & $18 / 19$ & -36 & -84 & -8 & 10.55 & .001 \\
\hline R fusiform $G$ & $18 / 19 / 37$ & 32 & -84 & -16 & 16.30 & .001 \\
\hline L SPL & 7 & -32 & -60 & 42 & 6.06 & .003 \\
\hline cingulate G/SMA & $32 / 6$ & 4 & 4 & 48 & 5.33 & .005 \\
\hline L inferior frontal $G$ & 44 & -56 & 8 & 36 & 4.9 & .005 \\
\hline L cerebellum & & -36 & -64 & -28 & 16.59 & .001 \\
\hline $\mathrm{R}$ cerebellum & & 36 & -64 & -36 & 13.37 & .001 \\
\hline
\end{tabular}

MNI coordinates and $T$ value for the peak location in a particular identified anatomical cluster $(p<.001 ; 10$ voxels spatial extent) for the statistically significant differences of the corresponding activated regions. Reported are the corrected $p$ values for each cluster. BA $=$ approximate Brodmann's area; $\mathrm{R}=$ right hemisphere; $\mathrm{L}=$ left hemisphere; $\mathrm{G}=$ gyrus; $\mathrm{SPL}=$ superior parietal lobe; SMA = supplementary motor area.

and the near-synonym activated their respective phonological representations (Jescheniak \& Schriefers, 1998). Another class of models, termed cascade or spreading activation models (Peterson \& Savoy, 1998; Dell, 1986; Stemberger, 1985), can easily accommodate the present set of results. As semantic features of the corresponding words in the two languages of bilinguals are identical, a high degree of competition would be predicted for such words by spreading activation models.

The degree to which the lemma and phonological representation in the nontarget language are activated might strongly depend on individual factors of the speaker, that is, to what degree s/he uses both languages concurrently from day to day, and on situational factors, such as mixed language or monolingual environments. The present study with alternating German- and Spanish-naming blocks created an extreme mixed language situation, as subjects were required to name the same pictures either in Spanish or in German on alternating blocks. It is interesting to note that previous experiments (Colomé, 2001; Costa et al., 2000) supporting phonological interference in language production have used fluent Catalan-Spanish bilinguals, who live in a strongly mixed language context with about equal presence of Catalan and Spanish in everyday life. It remains to be determined to what extent these results can be generalized to monolingual environments, in which monolingual speakers are only required to produce words in one of their languages.

To summarize, pronounced interference between languages is present in bilinguals required to name pictures in a strongly mixed language environment, such as simulated in the current experiment. Interestingly, Bialystok (1999) has suggested that bilingual children might develop enhanced cognitive control mechanisms, because they are faced with switching and attentional control demands from early on. If this was true, future studies should more closely inspect the interplay between control/executive brain mechanisms and the selection/ inhibition of language lexicons in bilinguals.

\section{METHODS}

All procedures were cleared by the institutional review board of the University of Magdeburg, Germany.

\section{Subjects}

Fourteen native monolingual speakers of German (11 women, mean age $24.8 \pm 2.0$ years) and 18 Ger- 
man-Spanish bilinguals (10 women, mean age $23.7 \pm$ 4.0 years) participated in the ERP experiment. A different group of 11 German-Spanish bilinguals ( 2 women, mean age $26.1 \pm 2.3$ years) and 11 German monolingual speakers ( 4 women, mean age $25.4 \pm 2.1$ years) were recruited for the fMRI experiment. All subjects were right-handed, healthy, and students at the University of Hannover or at technical schools. Bilinguals had either been born in Germany to Spanish parents or had grown up there since their early childhood years. All of them had used Spanish at home during childhood either exclusively or in conjunction with German but had visited German kindergarten and schools. Spanish can be considered the native language in the bilinguals, although at the time of study, German (i.e., the nonnative language) was reportedly the more fluent language. The results of a questionnaire (Weber-Fox \& Neville, 1996) revealed a rather balanced use of the languages in the bilingual group (ERP group: $3.0 \pm 0.6$; fMRI group: $4 \pm 0.9$, 7-point scale with $1=$ German only; 7 = Spanish only). Subjects were also asked to rate several language skills $(4=$ perfect; $3=$ good; 2 = sufficient; $1=$ meager). In German-Spanish, the corresponding means were the following: ERP group: comprehension 3.9/3.0, reading 3.9/2.8, speaking 3.8/2.9, and writing 3.6/2.5; fMRI group: comprehension 3.8/3.3, reading 3.7/3.2, speaking 3.8/3.2, and writing 3.4/3.3. In addition, the Boston Naming Test was applied in the fMRI group (Kohnert, Hernandez, \& Bates, 1998), which requires naming of 60 pictures. The scores for the bilingual group were $54.7 \pm 4.6$ for German and $48.4 \pm 5.6$ for Spanish $[t(10)=3.37, p<.01]$. The German naming score of the monolingual group was slightly higher [58.7 $\pm 0.64, t(20)=2.84, p<.01]$. Although bilinguals had better naming abilities in German, their Spanish-naming scores still were considerably higher than those of other (English-Spanish) bilingual groups reported recently, which ranged between 30 and 40 (Moreno, Federmeier, \& Kutas, 2002; Hernandez, Dapretto, et al., 2001; Hernandez, Martinez, et al., 2000; Kohnert et al., 1998).

In the ERP experiment, six bilingual and two monolingual subjects were lost because of excessive artifacts or technical problems.

\section{Event-related Brain Potentials Experiment}

Subjects viewed black on white line drawings that were presented in the middle of a video monitor. Each trial had the following structure: First, a fixation point appeared in the center of the screen (random duration between 1000 and $2000 \mathrm{msec}$, mean $1500 \mathrm{msec}$ ), which was replaced by a picture that remained on the screen for $1500 \mathrm{msec}$. This was followed by the fixation point starting the next trial. Thus, a single trial had a mean duration of $3000 \mathrm{msec}$. Pictures subtended $8^{\circ} \times 8^{\circ}$ of visual angle at the viewing distance of $1.1 \mathrm{~m}$. Before each experimental block, 20 practice trials were administered. The following experimental block comprised 100 trials and lasted 5 min.

For each picture, participants were required to make a go/no-go response depending on whether the first letter of the name was a vowel or consonant. In each block, half of the trials required a go-response, whereas the other half were no-go trials. Pictures were chosen such that names in Spanish and German bore no phonological similarity ("noncognates"). Moreover, pictures were selected such that half began with a vowel and the other half with a consonant in both languages. Finally, half of the words coincided with regard to the vowel/consonant criterion in both languages, whereas the other half did not. In total, 100 critical picture stimuli ( 25 word in each group) were selected: noncoincidence group: German [c]-Spanish [v] (e.g., Trichter-embudo [English: funnel]) and German [v]-Spanish [c] (e.g., Eidechselagarto [English: lizard]); coincidence group: German [v]-Spanish [v] (e.g., Esel-asno [English: donkey]), and German [c]-Spanish [c] (e.g, Kerze-vela [English: can$d l e]$ ). Words were matched for frequency as closely as possible (Alameda \& Cuetos, 1995; Baayen, Piepenbrock, \& Van Rijn, 1993). The mean frequency of the words in German-Spanish was 16.1/13.3 per million for the noncoincidence condition and 16.2/15.5 per million for the coincidence condition.

Bilinguals had to produce the German and Spanish names in alternate blocks, with half of the bilinguals starting with Spanish. Monolingual German control subjects exclusively produced the German names. Prior to the experiment, participants were familiarized with the pictures, which were first shown with their name printed below. Participants were asked to study the pictures and their appropriate names. This was done to avoid false naming during the experiment proper (e.g., bawk for eagle). To ensure that the correct names would be produced during the experiment, subjects had to name the pictures aloud in an additional practice run. Each block began with 20 practice trials (different pictures not used in the main experiment), after which 100 experimental trials were presented. Each subject received six experimental blocks in each language (monolingual subjects: six blocks of German only) with the go/no-go, vowel/consonant decisions, and response hands systematically rotated. The sequences of pictures were randomized in every block and for each subject.

\section{Event-related Brain Potentials Recording and Data Analysis}

The electroencephalogram was recorded from the scalp using 29 tin electrodes mounted in an elastic cap and positioned at standard locations. All scalp electrodes were rereferenced off-line to the average activity at the two mastoid processes. Vertical eye movements were 
monitored with an electrode below the right eye. All electrode impedances (electroencephalogram and electrooculogram) were kept below $5 \mathrm{k} \Omega$. The electrophysiological signals were filtered with a bandpass of 0.01$70 \mathrm{~Hz}$ (half-amplitude cutoffs) and digitized at a rate of $250 \mathrm{~Hz}$. Trials in which base-to-peak electrooculogram amplitude exceeded $50 \mu \mathrm{V}$, amplifier saturation occurred, or the baseline shift exceeded $200 \mu \mathrm{V} / \mathrm{sec}$ were automatically rejected off-line (mean percentage of rejection was $21.9 \%$ for the bilingual group and $13.7 \%$ for the monolingual group).

Correct trials were averaged separately for each condition for epochs of $1024 \mathrm{msec}$ including a 100-msec prestimulus baseline. Mean amplitudes were computed for different time windows, which were subjected to ANOVAs as specified in the result section. To accommodate topographical effects sets of ANOVAs were calculated for different groups of electrodes: midline $(\mathrm{Fz}, \mathrm{Cz}$, $\mathrm{Pz})$ and parasagittal (Fp1/2, F3/4, C3/4, P3/4, O1,2). A third set of ANOVAs on temporal (F7/8, T3/4, T5/6) electrodes was calculated but did not reveal additional information and has therefore been omitted in the result section.

Anteriority and hemisphere were introduced as a within-subject factors as appropriate. For all statistical effects involving two or more degrees of freedom in the numerator, the Huynh-Feldt epsilon correction was used. All ERP waveforms displayed in the figures were digitally filtered using a low-pass filter with a 6-Hz half-power cut-off. However, mean amplitudes for statistical analysis were computed with unfiltered waveforms.

\section{Event-related Functional Magnetic Resonance Imaging Experiment}

The same paradigm was used as in the ERP experiment with the following changes: Only 96 (instead of 100) experimental trials were used and an additional 30 fixation trials were introduced into the stimulation sequence. An experimental run thus lasted $[96+30] \times$ $3 \mathrm{sec}=378 \mathrm{sec}$. In the fixation trials, the fixation point only was presented for $3 \mathrm{sec}$. Training trials preceding the first block were administered without scanning. The order of presentation of the experimental conditions was pseudorandomized. Six blocks were performed by every subject of the bilingual group, alternating languages, as in the ERP experiment. Monolinguals received only three blocks.

Imaging was performed with a neuro-optimized GE Signa LX 1.5 T system (General Electric, Milwaukee, WI) with standard quadrature head coil. Visual images were back-projected onto a screen by an LED projector and participants viewed the images through a mirror on the head coil. Magnet-compatible response buttons were used. Conventional high resolution structural images (RF-spoiled GRASS sequence, 60-slice sagittal, 2.8-mm thickness) were followed by functional images sensitive to blood oxygenation level-dependent contrast (echoplanar $\mathrm{T} 2 *$-weighted gradient-echo sequence, $\mathrm{TR}=$ $1500 \mathrm{msec}, \mathrm{TE}=40 \mathrm{msec}$, flip angle $=90^{\circ}$ ).

Each functional run consisted of 254 sequential whole-brain volumes comprising 16 axial slices aligned to the plane intersecting the anterior and posterior commissures, $3.125-\mathrm{mm}$ in-plane resolution, $7-\mathrm{mm}$ thickness, 1-mm gap between slices. Volumes were acquired continuously; the five first volumes were discarded to allow for T1 equilibration effects. To allow precise coregistration of functional data, a separate T1weighted echo-planar image (EPI) was acquired covering the whole volume (inversion recovery-prepared EPI sequence).

Different preprocessing steps were implemented using Statistical Parametric Mapping (SPM99, Friston, Fletcher, et al., 1998; Friston, Frith, Turner, \& Frackowiak, 1995). First, for each volunteer, functional volumes were phase-shifted in time with reference to the first slice to minimize purely acquisition-dependent signal variations across slices. Second, head-movement artifacts were corrected based on an affine rigid body transformation with reference to the first image of the first run. Third, structural and functional data were spatially normalized to an EPI template based on the Montreal Neurological Institute (MNI) reference brain (Cocosco, Kollokian, Kwan, \& Evans, 1997), an approximation of canonical space (Talairach \& Tournoux, 1988), using a 12-parameter affine transformation along with a nonlinear transformation using cosine basis functions. Functional EPI volumes were resampled into $4-\mathrm{mm}^{3}$ voxels and then spatially smoothed with an $8-\mathrm{mm}$ full-width half-maximum isotropic Gaussian Kernel to accommodate residual anatomical differences across volunteers.

For the statistical model, an event-related design matrix including all conditions of interest was specified using the canonical hemodynamic response function for all event types (Friston, Fletcher, et al., 1998). The data were high-pass filtered, smoothed temporally with a 4-sec full-width half-maximum Gaussian kernel, and rescaled to the global mean. Significant differences in hemodynamic responses were validated using the linear model approach as implemented in SPM99. Effects were estimated using a subject-specific fixed-effects model. Linear contrasts were used to obtain subjectspecific estimates for each effect. For group analysis, these estimates were entered in a second-level analysis treating subjects as a random effect. Only clusters with a significant $p<.001$ corrected for multiple comparisons are reported unless otherwise mentioned. The maxima of suprathreshold regions were localized by rendering them onto the volunteers' normalized T1 structural images on the MNI reference brain (Cocosco et al., 1997). Maxima and all coordinates were reported in MNI coordinates, as used by SPM99. 


\section{Acknowledgments}

This work was supported by DFG grants of the T. F. Münte. The first author also received support from the Spanish government.

Reprint requests should be sent to Thomas F. Münte, Department of Neuropsychology, Otto von Guericke University, Universitätsplatz 2, Gebäude 24, 39106 Magdeburg, Germany, or via e-mail: thomas.muente@medizin.uni-magdeburg.de.

The data reported in this experiment have been deposited in the fMRI Data Center (www.fmridc.org). The accession number is $2-2004-1183 \mathrm{C}$.

\section{Note}

1. These activations emerged only when results were not corrected at the cluster level. This interaction Phonology $x$ Go/No-go was not expected for the monolingual group. It is significant between 200 and $600 \mathrm{msec}$. It must be related to a general small increase in the phonological noncoincidence condition even present in the first 200 msec compared with a decrease of the same condition in no-go trials (see Figure 3 ). In the 200- to 400-msec interval at midline locations: go coincidence, $2.0 \pm 5.1 \mu \mathrm{V}$; go noncoincidence, $1.6 \pm 5.2 \mu \mathrm{V}$; no-go coincidence, $1.6 \pm 5.3 \mu \mathrm{V}$; and no-go noncoincidence, $2.13 \pm 5.0 \mu \mathrm{V})$. These effects are mostly related to differences in the stimuli characteristics used in the coincidence and noncoincidence condition.

\section{REFERENCES}

Alameda, J. R., \& Cuetos, F. (1995). Diccionario de frecuencias de las unidades linguisticas del castellano. Oviedo: Servicio de Publicaciones Universidad de Oviedo.

Baayen, R. H., Piepenbrock, R., \& Van Rijn, H. (1993). The CELEX lexical database. Philadelphia: University of Pennsylvania, Linguistic Data Consortium.

Baddeley, A., Emslie, H., Kolodny, J., \& Duncan, J. (1998). Random generation and the executive control of working memory. Quarterly Journal of Experimental Psychology, A, 51, 819-852.

Bialystok, E. (1999). Cognitive complexity and attentional control in the bilingual mind. Child Development, 70 , 636-644.

Botvinick, M. M., Nystrom, L., Fissell, K., Carter, C. S., \& Cohen, J. D. (1999). Conflict monitoring versus selection-for-action in the anterior cingulate cortex. Nature, 402, 179-181.

Carter, C. S., Braver, T. S., Barch, D. M., Botvinick, M. M., Noll, D. C., \& Cohen, J. D. (1998). Anterior cingulate cortex, error detection, and the on-line monitoring of performance. Science, 280, 747-749.

Carter, C. S., Macdonald, A. M., Botvinick, M., Ross, L. L., Stenger, V. A., Noll, D., \& Cohen, J. D. (2000). Parsing executive processes: Strategic vs. evaluative functions of the anterior cingulate cortex. Proceedings of the National Academy of Sciences, U.S.A., 15, 1944-1948.

Chee, M. W. L., Caplan, D., Soon, C. S., Sriram, N., Tan, E. W. L., Thiel, T., \& Weekes, B. (1999). Processing of visually presented sentences in Mandarin and English studied with fMRI. Neuron, 23, 127-137.

Chee, M. W. L., Tan, E. W., \& Thiel, T. (1999). Mandarin and English single word processing studied with functional magnetic resonance imaging. Journal of Neuroscience, 19, 3050-3056.
Cocosco, C. A., Kollokian, V., Kwan, R. K. S., \& Evans, A. C. (1997). BrainWeb: Online interface to a 3D MRI simulated brain database. Neuroimage, 5, S425.

Colomé, A. (2001). Lexical activation in bilinguals' speech production: Language-specific or language-independent? Journal of Memory and Language, 45, 721-736.

Costa, A., Caramazza, A., \& Sebastian-Galles, N. (2000). The cognate facilitation effect: Implications for models of lexical access. Journal of Experimental Psychology: Learning, Memory and Cognition, 26, 1283-1296.

de Bot, K. (1992). A bilingual production model: Levelt's "speaking" model adapted. Applied Linguistics, 13, 1-24.

Dell, G. S. (1986). A spreading-activation theory of retrieval in sentence production. Psychological Review, 93, 283-321.

Dell, G. S., \& O'Seaghdha, P. G. (1992). Stages of lexical access in language production. Cognition, 42, 287-314.

D’Esposito, M., Detre, J. A., Alsop, D. C., Shin, R. K., Atlas, S., \& Grossman, M. (1995). The neural basis of the central executive system of working memory. Nature, 378, 279-281.

Dove, A., Pollmann, S., Schubert, T., Wiggins, C. J., \& von Cramon, D. Y. (2000). Prefrontal cortex activation in task switching: An event-related fMRI study. Cognitive Brain Research, 9, 103-109.

Dreher, J. C., Koechlin, E., Ali, S. O., \& Grafman, J. (2002). The roles of timing and task order during task switching. Neuroimage, 17, 95-109.

Fabbro, F., Skrap, M., \& Aglioti, S. (2000). Pathological switching between languages after frontal lesions in a bilingual patient. Journal of Neurology, Neurosurgery and Psychiatry, 68, 650-652.

Friston, K. J., Fletcher, P., Josephs, O., Holmes, A., Rugg, M. D., \& Turner, R. (1998). Event-related fMRI: Characterizing differential responses. Neuroimage, 7, 30-40.

Friston, K. J., Frith, C. D., Turner, R., \& Frackowiak, R. S (1995). Characterizing evoked hemodynamics with fMRI. Neuroimage, 2, 157-165.

Frith, C. D., Friston, K. J., Liddle, P. F., \& Frackowiak, R. S. J. (1993). A PET study of word finding. Neuropsychologia, 29, $1137-1148$.

Garavan, H., Ross, T., Li, S., \& Stein, E. (2000). A parametric manipulation of central executive functioning. Cerebral Cortex, 10, 585-592.

Garavan, H., Ross, T. J., \& Stein, E. A. (1999). Right hemispheric dominance of inhibitory control: An event-related functional MRI study. Proceedings of the National Academy of Sciences, U.S.A., 96, 8301-8306.

Green, D. W. (1986). Control, activation and resource: A framework and a model for the control of speech in bilinguals. Brain and Language, 27, 210-223.

Grosjean, F. (1997). Processing mixed languages: Issues, findings and models. In A. De Groot \& J. Kroll (Eds.), Tutorials in bilingualism: Psycholinguistic perspectives (pp. 225-254). Mahwah, NJ: Erlbaum.

Hermans, D., Bongaerts, T., de Bot, K., \& Schreuder, R. (1998). Producing words in a foreign language: Can speakers prevent interference from their first language? Bilingualism, $1,213-229$

Hernandez, A. E., Dapretto, M., Mazziotta, J., \& Bookheimer, S. (2001). Language switching and language representation in Spanish-English bilinguals: An fMRI study. Neuroimage, $14,510-520$.

Hernandez, A. E., Martinez, A., \& Kohnert, K. (2000). In search of the language switch: An fMRI study of picture naming in Spanish-English bilinguals. Brain and Language, 3 , 421-431.

Indefrey, P., \& Levelt, W. M. J. (2004). The spatial and temporal signatures of word production components. Cognition, 92, 101-144. 
Jescheniak, J., \& Schriefers, H. (1998). Discrete serial versus cascaded processing in lexical access in speech production: Further evidence from the coactivation of near-synonyms. Journal of Experimental Psychology: Learning, Memory, and Cognition, 24, 1256-1274.

Kempen, G., \& Huijberts, P. (1983). The lexicalization process in sentence production and naming: Indirect election of words. Cognition, 14, 185-209.

Klein, D., Milner, B., Zatorre, R., Zhao, V., \& Nikelski, J. (1999). Cerebral organization in bilinguals: A PET study of Chinese-English verb generation. NeuroReport, 10, 2841-2846.

Kohnert, K. J., Hernandez, A. E., \& Bates, E. (1998). Bilingual performance on the Boston naming test: Preliminary norms in Spanish and English. Brain and Language, 65, 422-440.

Konishi, S., Nakajima, K., Uchida, Y., Kikyo, H., Kameyama, M., \& Miyashita, Y. (1999). Common inhibitory mechanism in human inferior prefrontal cortex revealed by event-related functional MRI. Brain, 122, 981-991.

Konishi, S., Nakajima, K., Uchida, I., Sekihara, K., \& Miyashita, Y. (1998). No-go dominant brain activity in human inferior prefrontal cortex revealed by functional magnetic resonance imaging. European Journal of Neuroscience, 10, 1209-1213.

Levelt, W. J. M. (1989). Speaking: From intention to articulation. Cambridge: MIT Press.

Levelt, W. J. M., Roelofs, A., \& Meyer, A. S. (1999). A theory of lexical access in speech production. Behavioral and Brain Sciences, 22, 1-75.

Levelt, W. J .M., Schriefers, H., Vorberg, D., Meyer, A. S., Pechmann, T., \& Havinga, J. (1991). The time course of lexical access in speech production: A study of picture naming. Psychological Review, 98, 122-142.

Liddle, P. F., Kiehl, K. A., \& Smith, A. M. (2001). Event-related fMRI study of response inhibition. Human Brain Mapping, 12, 100-109.

Menon, V., Adleman, N. E., White, C. D., Glover, G. H., \& Reiss, A. L. (2001). Error-related brain activation during a go/nogo response inhibition task. Human Brain Mapping, 12, 131-143.

Moreno, E. M., Federmeier, K. D., \& Kutas, M. (2002). Switching languages, switching palabras (words): An electrophysiological study of code switching. Brain and Language, 80, 188-207.

Murtha, S., Chertkow, H., Beauregard, M., \& Evans, A. (1999). The neural substrate of picture naming. Journal of Cognitive Neuroscience, 11, 399-423.

Paradis, M. (1989). Bilingual and polyglot aphasia. In F. Boller \& J. Grafman (Eds.) Handbook of neuropsychology (vol. 2, pp. 117-140). Amsterdam: Elsevier.

Pardo, J. V., Pardo, P. J., Janer, K. W., \& Raichle, M. E. (1990). The anterior cingulate cortex mediates processing selection in the Stroop attentional conflict paradigm. Proceedings of the National Academy of Sciences, U.S.A., 87, 256-259.

Perani, D., Paulesu, E., Sebastian-Galles, N., Dupoux, E., Dehaene, S., Bettinardei, V., Cappa, S., Fazio, F., \& Mehler, J. (1998). The bilingual brain. Proficiency and age of acquisition of the second language. Brain, 121, 1841-1852.

Petersen, R., \& Savoy, P. (1998). Lexical selection and phonological encoding during language production:
Evidence for cascaded processing. Journal of Experimental Psychology: Learning, Memory and Cognition, 24, 539-557.

Pfefferbaum, A., Ford, J., Weller, B., \& Kopell, B. (1985). ERPs to response production and inhibition. Electroencephalography and Clinical Neurophysiology, 60, 423-434.

Poulisse, N., \& Bongaerts, T. (1994). First language use in second language production. Applied Linguistics, 15, $36-57$.

Price, C., Green, D., \& von Studnitz, R. (1999). A functional imaging study of translation and language switching. Brain, 122, 2221-2235.

Price, C. J., Wise, R. J., Warburton, E. A., Moore, C. J., Howard, D., Patterson, K., Frackowiak, R. S., \& Friston, K. J. (1996). Hearing and saying. The functional neuro-anatomy of auditory word processing. Brain, 119, 919-931.

Rodriguez-Fornells, A., Rotte, M., Heinze, H. J., Nosselt, T., \& Münte, T. F. (2002). Brain potential and functional MRI evidence for how to handle two languages with one brain. Nature, 415, 1026-1029.

Rodriguez-Fornells, A., Schmitt, B. M., Kutas, M., \& Münte, T. (2002). Electrophysiological estimates of the time course of semantic and phonological encoding during listening and naming. Neuropsychologia, 40, 778-787.

Schmitt, B. M., Münte, T., \& Kutas, M. (2000).

Electrophysiological estimates of the time course of semantic and phonological encoding during implicit picture naming. Psychophysiology, 37, 473-484.

Schmitt, B. M., Schiltz, K., Zaake, W., Kutas, M., \& Münte, T. F. (2001). An electrophysiological analysis of the time course of conceptual and syntactic encoding during tacit picture naming. Journal of Cognitive Neuroscience, 13, 501-522.

Schriefers, H., Meyer, A. S., \& Levelt, W. J. M. (1990). Exploring the time course of lexical access in language production: Picture-word interference studies. Journal of Memory and Language, 29, 86-102.

Stemberger, J. P. (1985). An interactive activation model of language production. In A. W. Ellis (Ed.), Progress in the psychology of language (vol. 1, pp. 143-186). Hove: Erlbaum.

Talairach, J., \& Tournoux, P. (1988). Co-planar stereotaxic atlas of the human brain. Stuttgart: Thieme.

Thorpe, S., Fize, D., \& Marlot, C. (1996). Speed of processing in the human visual system. Nature, 381, 520-522.

van Turennout, M., Hagoort, P., \& Brown, C. M. (1997). Electrophysiological evidence on the time course of semantic and phonological processes in speech production. Journal of experimental Psychology: Learning, Memory, and Cognition, 23, 787-806.

van Turennout, M., Hagoort, P., \& Brown, C. M. (1998). Brain activity during speaking: From syntax to phonology in 40 milliseconds. Science, 280, 572-574.

Weber-Fox, C., \& Neville, H. J. (1996). Maturational constraints on functional specializations for language processing: ERP and behavioral evidence in bilingual speakers. Journal of Cognitive Neuroscience, 8, 231-256.

Wheeldon, L. R., \& Levelt, W. J. M. (1995). Monitoring the time course of phonological encoding. Journal of Memory and Language, 34, 311-334. 